\title{
Research on Applications of Human Resource Information System in SMEs
}

\author{
Song $\mathrm{Wei}^{1, \mathrm{a}}$, and An Feng ${ }^{2, \mathrm{~b}}$ \\ ${ }^{1}$ College of Business Administration University of Science and Technology Liaoning Anshan, China \\ ${ }^{2}$ College of Business Administration University of Science and Technology Liaoning Anshan, China \\ asongwei0207@126.com, baf218@126.com
}

Keywords: Human Resource Information System ; Applications; Small and Medium Enterprise

\begin{abstract}
Nowadays, information technology and human resource management unite together more and more closely. Human resources information systems can play an important role in the modern enterprise management. But there are many problems in the application of human resource information systems in Chinese SMEs, including information content, information management, system evaluation, etc. We should take some measures to improve SMEs' human resources information system applications in China.
\end{abstract}

\section{Introduction}

At present, the development of information technology becomes more and more rapid, and it is widely used in various areas of human activity. Human Resource Information System(HRIS) is an important application of information technology in business management. Nowadays, more and more SMEs start to introduce HRIS in China, which helps SMEs to optimize their management and improve their efficiency. But there are still many problems in the HRIS applications, such as applications rang, systems evaluation, etc. We should take some measures to improve the application of HRIS in SMEs management, so that information technology may play a greater role in SMEs.

\section{Human Resource Information System and Its Main Functions}

The rise of human resource information systems and its evolution. Nowadays, human resource is considered to be the most valuable resource, and has become the ultimate source of core competitive advantage. Getting talents, then using and motivating them become the top priority of business human resource management. Many managers encountered a lot of trouble at this. Development and use of HRIS has made tremendous contribution to this issue.

HRIS began in the late 1960s, at that time, some large companies used computer technology to calculate the compensation and pay salaries. Along with the rapid development of computer technology, human resource management is combined with computer systems tools and database technology more and more deeply. Currently, HRIS covers all human resource management function modules (such as personal information, recruitment, training, career management, performance management, compensation and benefits administration, labor contracts and employee relationship management), it is considered to be a process of information collection, storage, analysis and reporting. HRIS is a valid method to obtain relevant information timely for decision-making ${ }^{[1]}$.

HRIS 's main Functions. Firstly, improving human resource management efficiency. HRIS can help enterprises establish electronic personnel files, estimate employees knowledge, skills, abilities, experience better, quickly predict the company's future human resource needs. In addition, through HRIS (such as compensation management system, personnel recruitment and training systems, performance management systems, etc.), we can reduce time consumed on routine work, improve work efficiency significantly ${ }^{[2]}$.Secondly, integrating human resource management business processes. HRIS covers a series of work module including post management, performance and salary management, training plan, succession planning, etc. Using the Internet and personal computers, we can realize the human resources management work systematic, modelling and integration. In this 
process, human resource management processes can be reconstructed and standard, its business flow become more smoothly, and its efficiency can be improved a lot. HRIS establishes one to one, one to many, many to many forms association among the module databases, thus build a intelligent management system based on the center of HRIS ,this system can radiate to the OA systems, production control systems, business management systems, etc., finally achieve a wider range of business integration. Thirdly, providing value-added services for enterprises and employees. Fundamental task of human resource management is to provide loyal service to their customers, corporate management and employees ${ }^{[3]}$. HRIS may provide timely, accurate, concise, relevant and complete reports and information for business management personnel, this can provide the basis for the relevant personnel decisions, particularly for human resources planning and policy from a strategic point of view. In addition, through HRIS, employees can obtain information more easily, this supports employee participation in management. HRIS provides staff with more extensive value-added services, to achieve common development of enterprises and employees.

The Application Status of Human Resource Information System in SMEs

With the recent development of computer-related technology and extensive use of ERP systems, more and more SMEs start using HRIS to improve the level and efficiency of human resource management. However, the application of HRIS in Chinese SMEs is basically in the transaction level. It emphasizes on static management about the number of personnel, fails to provide the necessary information to support enterprise decision ${ }^{[4]}$. Therefore, the application of HRIS in China SMEs seems very weak. Main problems are as following aspects.

From the matching degree between HRIS and enterprises, most SMEs failed to build up HRIS suitable for the actual situation of the enterprise. HRIS involves all aspects of human resources management work, which is very complex, and the cost of information collection is correspondingly higher. In the process of building HRIS and its application, many Chinese SMEs ignore their own development, management level, relevant management personnel quality, they are unable to assess the exact needs of enterprise scientifically and rationally. Some companies buy human resources management software blindly, and lack awareness and ability of secondary development, these have produced a disjoint between HRIS and business needs, it is difficult to play HRIS more powerful role.

Judging from the content of information, the application range of HRIS is relatively narrow. Most SMEs use HRIS to capture and store the workers file, establish the electronic personnel files; some companies do the performance evaluation, as well as compensation management. As for the recruitment, training and development, career management, performance management, employee relations management and many other HR modules, most of the company's HRIS involves less. It is not enough to fully understand the situation and the proper use of human resources.

From the view of information management and utilization, most of the HRISs for SMEs only refer personnel and compensation information, to some extent they are simple. HRIS can only provide a basic routine queries about the status of personnel, salary accounting and statistical reports, it can not provide a combination inquiries of a variety of conditions. And most of the company's HRISs lack of human resources analysis of historical data, fail to provide enterprises with good human resource forecasting and decision-making functions. In addition, HRIS can not be able to work well with other enterprise management systems (such as office automation systems, business management systems, etc.) in direct contact, this results in the HRIS staying in the low-level, which affects the human resource decision quality, speed and level, hinder the enterprise's survival and development.

From the perspective of HRIS evaluation, most Chinese SMEs only focus on HRIS usage, contempt its evaluation and improvement. The establishment and application of HRIS not only include system planning, system design and implementation, and also include evaluation of information systems. That is to say, we need to evaluate the HRIS's safety, reliability, stability, economic effects, process integration, customer satisfaction and other indicators, then put forward the corresponding improvement program. However, most of the Chinese SMEs are in the stages of importing and learning to use, they pay little attention to the effectiveness evaluation of HRIS. This 
makes enterprise human resources management work lost in the tide of information, and also lost the goal and direction.

\section{Countermeasures to improve application efficiency of SME's HRIS}

According to enterprise actual needs, building HRIS reasonably. Any information system design and application determine what it will be able to bring to the enterprise. Therefore, in the planning of HRIS, enterprises must have a clear business, that is what they needs, and remember these needs in all aspects of system design and application. Enterprises should consider its development strategy and the existing scale, the mastery of human resources information, and also consider the potential for replicating and transferring information within the enterprise, human resources management department's utilization and expectations of HRIS and other factors. Eventually, companies decide the functionality expectations of HRIS and the corresponding requirements about hardware and software. For this reason, business leaders should recognize that the new trends of HRIS, realize the need to invest, make the right decisions. General staff should be aware of the impact to their own development in information management model, have a good attitude to avoid erroneous understanding, join in the construction and use of HRIS actively ${ }^{[5]}$.

Focusing on process integration and standardization, achieving system integration at the corporate level. A good HRIS should be an efficient, versatile, easy-to-use human resources development and management solution. The system should be able to handle institutional settings, job settings, job evaluation, performance evaluation, compensation management, training management, HR planning, recruitment, labor contracts and other human resource development and management work. It can help SMEs form more complete and standardized human resource management processes through the integration of information systems. In addition, HRIS also needs to connect with production system, OA system, business system and other systems through various interfaces, so can realize the system optimization and integration in entire company. This model of development and usage is shown in Fig. $1^{[6]}$.

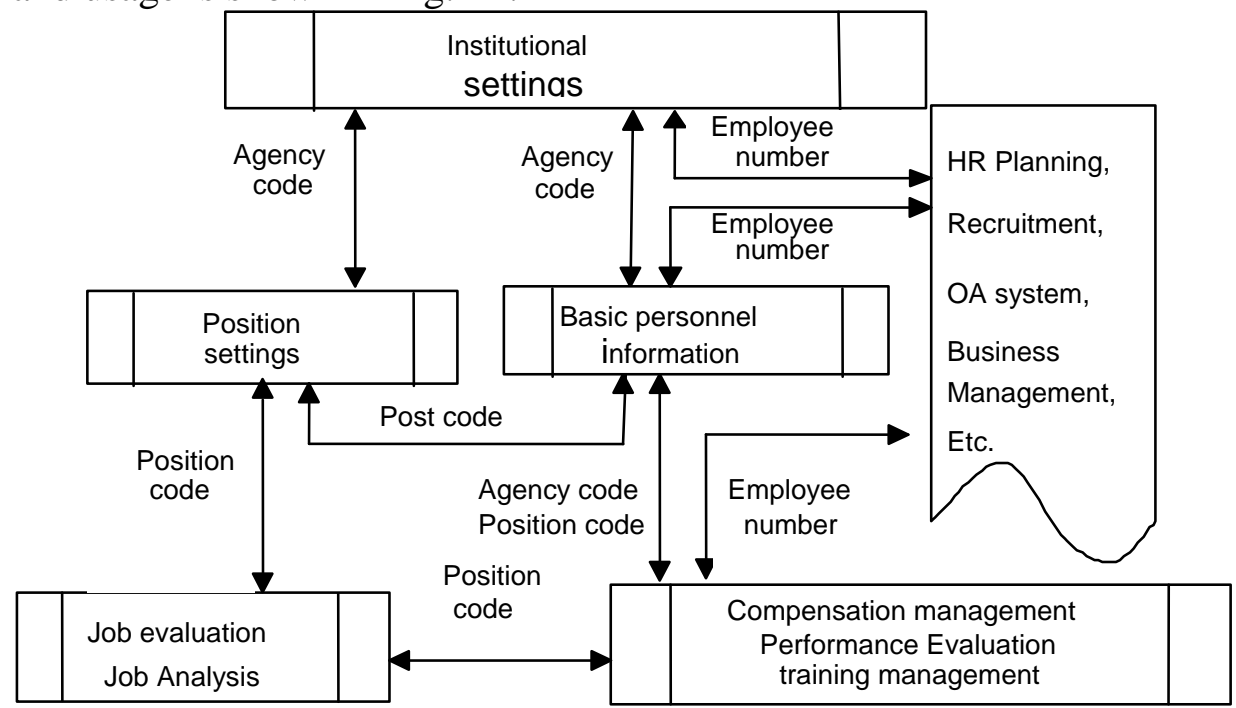

Fig.1: Human resource information system mode architecture diagram

Broadening the information content, implementing human resource management in a more extensive range. HRIS is based on computer technology, it covers all the functions of human resource management modules. HRIS integrates human resources strategy and planning, staff recruitment and evaluation, staff training management, career management, performance management, compensation and benefits administration and employee relationship management organically, this makes it play a greater role in the enterprise management. So, along with the continuous growth of SMEs in China, more and more enterprises start using the HRIS, they should improve the level of this application, that is to say, companies should apply more human resources management module, not only file management, compensation management and other simple 
applications. This comprehensive application should pay more attention to the dynamic information of employees, reflect the ability enhancement of employees in the work process in order to help SMEs use human resources better. In addition, enterprises should also pay more attention to the historical data analysis, use HRIS better to service for the enterprise forecasting and decision-making.

Constructing evaluation index system to evaluate HRIS comprehensively. This evaluation to enterprise HRIS construction and application is to examine its business and management implications on the enterprise objectives and strategies. The SMEs should evaluate HRIS applications from the full range, comparing to the enterprise goals find problems in the application process. Then enterprises need to cooperate with software vendors to improve HRIS functionality. The common evaluation indexes are shown in Fig. 2.

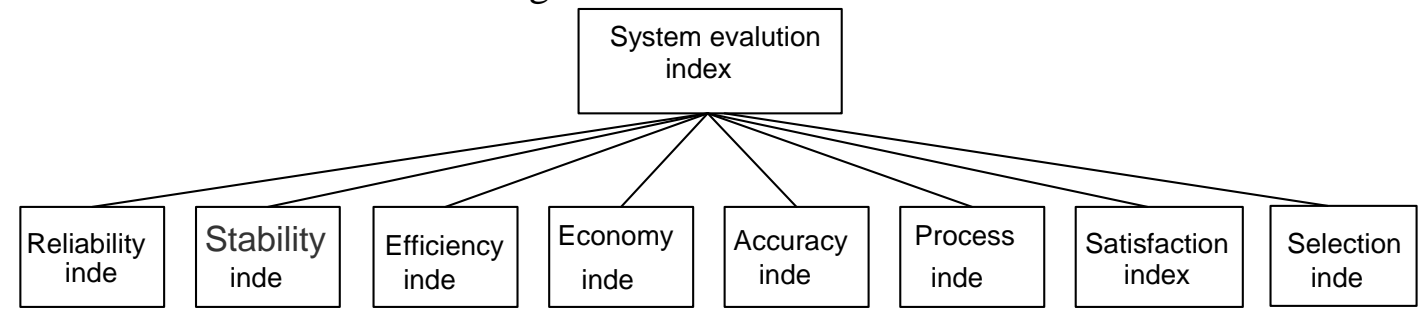

Fig. 2: Human Resource Information System Evaluation System

\section{Conclusions}

First, SMEs should clarify their real needs to HRIS, and keep the needs in mind in the whole process of HRIS introduction and implication. HRIS should meet the SMEs needs, and service for SMEs better.

Secondly, SMEs should expand HRIS applications, use HRIS help SMEs to take on more work in human resources management, especially in performance management, staff training, compensation management and other core work, so can achieve full use of human resources information system.

Finally, SMEs should strengthen the evaluation of human resource information systems. SMEs should establish an index system including security, stability and economic and other indicators, using the index system to evaluate HRIS can help SMEs identify the inadequacies in human resources information system applications, and also find specific areas and methods for improvement.

\section{Acknowledgments}

This work is supported by Liaoning Planning Fund of Philosophy and Social Science under Grant NO. L12CJY039.

\section{References}

[1] Shunming Zhao: Human Resource Strategy and Planning(the third edition), edited by Ren Min University of China, 2012, in press.

[2]Yang Yang, Hongpeng Jiang: Swore Impetuous Human Resources Management Information, Human Resource, 2004(6).

[3]Arthur - W • Small Sherman, George - W • Bo Land, Scott • A • Snell: Human Resource Management. Zhang Wenxian Translation, Dalian: Dongbei University of Finance and Economics Press, 2001.

[4]Hao Cai: Evolution and Prospects of Human Resource Information System, Journal of Northwestern Polytechnic University( Social Sciences) ,Vol·26,2006.

[5] Yajun Lai: Explore on the Application of Human Resource Management Information Systems, Information and Computer, in January 2012.

[6] Junhua Li, Hongbo Tan: Research and Development of Enterprise Human Resource Information System Model in the Information Economy, Journalof South China Normal University(Social Sciences edition),No.6,2012. 